\title{
Management of stage I and II nonsmall cell lung cancer
}

\author{
Fiona McDonald ${ }^{1,6}$, Michèle De Waele ${ }^{2,6}$, Lizza E. L. Hendriks ${ }^{3,6}$, \\ Corinne Faivre-Finn ${ }^{4,5}$, Anne-Marie C. Dingemans ${ }^{3}$ and Paul E. Van Schil ${ }^{2}$ \\ Number 2 in the series "Multidisciplinary questions in thoracic oncology: \\ the team experience" Edited by J-P. Sculier
}

\begin{abstract}
Affiliations: ${ }^{1}$ Dept of Radiotherapy, Royal Marsden NHS Foundation Trust, Sutton, UK. ${ }^{2}$ Dept of Thoracic and Vascular Surgery, Antwerp University Hospital, Antwerp, Belgium. ${ }^{3}$ Dept of Respiratory Disease, Maastricht University Medical Centre, Maastricht, the Netherlands. ${ }^{4}$ Manchester Academic Health Science Centre, Institute of Cancer Sciences, Manchester Cancer Research Centre (MCRC), University of Manchester, Manchester, UK. ${ }^{5}$ Radiotherapy Related Research, Christie NHS Foundation Trust, Manchester, UK. ${ }^{6}$ These authors equally contributed to this manuscript.
\end{abstract}

Correspondence: Paul E. Van Schil, Dept of Thoracic and Vascular Surgery, Antwerp University Hospital, Wilrijkstraat 10, B-2650 Edegem, Antwerp, Belgium. E-mail: paul.van.schil@uza.be

@ERSpublications

Early stage lung cancer treatment needs multidisciplinary cooperation between physicians, oncologists and surgeons http://ow.ly/EKxe304XhMR

Cite this article as: McDonald F, De Waele M, Hendriks LEL, et al. Management of stage I and II nonsmall cell lung cancer. Eur Respir J 2017; 49: 1600764 [https://doi.org/10.1183/13993003.00764-2016].

ABSTRACT The incidence of stage I and II nonsmall cell lung cancer is likely to increase with the ageing population and introduction of screening for high-risk individuals. Optimal management requires multidisciplinary collaboration. Local treatments include surgery and radiotherapy and these are currently combined with (neo)adjuvant chemotherapy in specific cases to improve long-term outcome. Targeted therapies and immunotherapy may also become important therapeutic modalities in this patient group. For resectable disease in patients with low cardiopulmonary risk, complete surgical resection with lobectomy remains the gold standard. Minimally invasive techniques, conservative and sublobar resections are suitable for a subset of patients. Data are emerging that radiotherapy, especially stereotactic body radiation therapy, is a valid alternative in compromised patients who are high-risk candidates for surgery. Whether this is also true for good surgical candidates remains to be evaluated in randomised trials. In specific subgroups adjuvant chemotherapy has been shown to prolong survival; however, patient selection remains important. Neoadjuvant chemotherapy may yield similar results as adjuvant chemotherapy. The role of targeted therapies and immunotherapy in early stage nonsmall cell lung cancer has not yet been determined and results of randomised trials are awaited.

Received: April 152016 | Accepted after revision: Oct 042016

Earn CME accreditation by answering questions about this article. You will find these at erj.ersjournals.com/journal/cme Conflict of interest: Disclosures can be found alongside this article at erj.ersjournals.com

Previous articles in this series. No. 1: Malhotra J, Malvezzi M, Negri E, et al. Risk factors for lung cancer worldwide. Eur Respir J 2016; 48: 889-902.

Copyright @ERS 2017 


\section{Introduction}

Multimodality treatment of stage I and II nonsmall cell lung cancer (NSCLC) requires a delicate interplay between surgery, radiotherapy and chemotherapy. More recently, immunotherapy and targeted agents have emerged as potentially important treatment modalities. To determine management for each patient, a thorough knowledge is required of the natural history of disease, risk assessment of the individual patient, evaluation of the diagnostic and staging examinations available, multidisciplinary input into individualised treatment plans and, importantly, discussion of the risks and benefits of treatment options with the patient. To this end, every patient with presumed or proven lung cancer should be discussed within a dedicated multidisciplinary team (MDT) to ensure the optimal individualised therapeutic plan.

In this article, as part of the series on "Multidisciplinary questions in thoracic oncology", the different treatment modalities that are currently available for these patients are discussed in depth. The local modalities, surgery and radiotherapy, and their integration with systemic treatment are reviewed. Each co-author searched the literature over the past 10 years in their specific discipline. The main databases used were PubMed, Cochrane database and Web of Science. References of the selected papers and abstracts of major meetings were also screened for new, relevant data. As a broad area is covered, this manuscript cannot be considered a systematic review stricto sensu but a clear update is provided on management of stage I and II NSCLC. When applicable, levels of evidence are mentioned (table 1). Presently there are a number of grey areas, highlighting the need for further clinical research to provide high-level evidence for future recommendations.

\section{Diagnosis, patient selection and staging} Computed tomography screening

The incidence of early stage NSCLC is expected to increase due to wider availability of computed tomography scans and the introduction of screening in high-risk populations [1]. This will increase surgical workload. The higher risks of surgical morbidity and mortality in patients with multiple co-morbidities, coupled with an ageing population suggests that non-surgical management of early stage NSCLC is likely also to rise [2].

\section{Implication of changes in World Health Organisation pathological classification}

The new World Health Organization (WHO) classification of lung tumours, published in 2015, integrates immunohistochemistry into the classification of resected lung cancers [3]. A complete histological evaluation of the tumour is necessary for diagnosis and is of prognostic value. In this edition, the American Thoracic Society (ATS)/European Respiratory Society (ERS)/International Association for the Study of Lung Cancer (IASLC) classification of adenocarcinoma published in 2011 was included without changes [4]. New subcategories include adenocarcinoma in situ and minimally invasive adenocarcinoma. Complete histological review should be performed to look for invasive foci with measurement of invasion. The term bronchioloalveolar carcinoma, which gave rise to much confusion, is not used anymore. Subtypes of invasive adenocarcinoma should be listed with their relative percentage indicated. This classification also has profound surgical implications which are discussed in the surgical section [5].

\section{Implication of changes in 8th edition of tumour-node-metastasis classification}

In 2017, the 8th tumour-node-metastasis (TNM) classification of lung cancer will be introduced $[6,7]$. Important changes have been made in the $\mathrm{T}$ descriptor on the basis that larger tumours are associated with worse prognosis. $3 \mathrm{~cm}$ diameter remains the cut-off margin between T1 and T2; T1 is subdivided into T1a $(\leqslant 1 \mathrm{~cm})$, T1b $(1.1-2 \mathrm{~cm})$ and T1c $(2.1-3 \mathrm{~cm}) . \mathrm{T} 2$ is subdivided into T2a $(3.1-4 \mathrm{~cm})$ and T2b $(4.1-5 \mathrm{~cm})$. Tumours larger than $5 \mathrm{~cm}$ and $7 \mathrm{~cm}$ are categorised as $\mathrm{T} 3$ and T4, respectively. Using the entire database available for the 8th TNM classification, 5-year survival has improved (level C evidence). Overall survival by clinical and pathological stage for the 7th and 8th TNM classifications are given in tables 2 and 3, respectively, for comparison [6-8].

\section{TABLE 1 Levels of evidence}

\begin{tabular}{ll} 
Level & Description \\
\hline A & Randomised controlled trials with a consistent pattern and rich body of data \\
B & Randomised controlled trials with a limited number of patients or inconsistent results \\
C & Non-randomised trials, observational studies \\
D & Panel consensus judgment \\
E & Expert opinion
\end{tabular}


TABLE 2 Overall survival by stage according to the 7th tumour-node-metastasis (TNM) classification

Stage 7th edition

5-year survival for clinical stage

5-year survival for pathological stage

\begin{tabular}{lll}
\hline IA & $82 \%$ & $83 \%$ \\
IB & $66 \%$ & $71 \%$ \\
IIA & $52 \%$ & $57 \%$ \\
IIB & $47 \%$ & $49 \%$
\end{tabular}

7th TNM classification based on [8]

\section{Cardiopulmonary risk assessment}

All patients should be discussed in a MDT to decide which treatment option is most suitable on an individual basis. Although there is no clear definition of high-risk patients, it should be kept in mind that empiric selection of patients may deny optimal oncological management [9]. Even with modern computed tomographic and positron emission tomographic (PET) staging, pathological upstaging is seen in up to $30 \%$ of patients $[10,11]$. Multiple guidelines exist on selecting patients who are fit for surgery [12-14]. The second European Society for Medical Oncology (ESMO) consensus conference on lung cancer recommended detailed assessment of cardiac and pulmonary function in order to estimate surgical morbidity (level $\mathrm{C}$ evidence). Cardiac function is tested using the recalibrated thoracic revised cardiac risk index, made up of history of ischaemic heart disease and cerebrovascular disease, serum creatinine and whether the intended procedure is a pneumonectomy or not. Pulmonary function is determined by the percentage of predicted forced expiratory volume in $1 \mathrm{~s}$ (FEV1) and lung diffusion capacity (DLCO). When percentages are $<80 \%$ for either one, exercise testing is recommended (maximal oxygen consumption and split lung function) (level C evidence) [15]. Also, for patients undergoing radiotherapy and chemotherapy, cardiopulmonary function should be assessed. This is especially important in patients with low DLCO and poor performance status to decide whether they tolerate the anticipated treatment scheme or not.

\section{Lung cancer staging}

For a presumable clinical stage I or II NSCLC evaluation of locoregional lymph node spread and screening for distant metastases are required. This is mostly performed by PET-computed tomography scanning which provides anatomical and metabolic information. In case of suspicious lymph nodes or distant lesions, every effort should be made to obtain a pathological diagnosis by a minimally invasive technique (MIT) or invasive technique. Further lymph node evaluation is performed by endobronchial ultrasound or endoscopic ultrasound. In case results are negative, mediastinoscopy or thoracoscopy are the next steps (level D evidence). Recently, the European Society of Thoracic Surgeons (ESTS) updated guidelines for preoperative staging of NSCLC [16]. Also, for patients undergoing stereotactic body radiotherapy (SBRT) lymph node staging is recommended [17]

\section{Treatment modalities}

\section{Surgery}

Introduction

Surgical intervention remains the gold standard for the approximately $30 \%$ of NSCLC patients who present with resectable stage I and II disease [18] and who are functionally operable (level C evidence) [5, 15, 19].

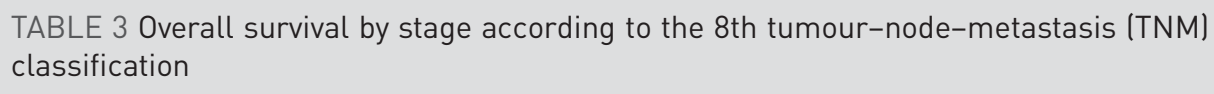

\begin{tabular}{lll}
\hline IA1 & $92 \%$ & $90 \%$ \\
IA2 & $83 \%$ & $85 \%$ \\
IA3 & $77 \%$ & $80 \%$ \\
IB & $68 \%$ & $73 \%$ \\
IIA & $60 \%$ & $65 \%$ \\
IIB & $53 \%$ & $56 \%$ \\
\hline
\end{tabular}

8th TNM classification based on $[6,7]$ 
The extent of resection and precise surgical approach are the subject of discussion. Additionally, with the advances in newer ablative techniques, their role in early stage disease is currently debated, especially in medically compromised patients. In this section, the indications for sublobar resections (SLR), sleeve resections and MIT by video-assisted thoracic surgery (VATS) and robot-assisted thoracic surgery (RATS) are discussed.

Conservative interventions: SLR and bronchoplastic procedures

Lobectomy has remained the standard of care for resection of early stage NSCLC since the prospective randomised Lung Cancer Study Group trial, comparing lobectomy with SLR (anatomical segmentectomy or wedge resection) for stage I NSCLC, which was published in 1995 [20]. The limited resection group had a three-fold increased incidence in local recurrence $(\mathrm{p}=0.008)$, a $30 \%$ increase in overall death rate $(\mathrm{p}=0.08)$ and a $50 \%$ increase in cancer-related death $(\mathrm{p}=0.09)$ compared with patients undergoing lobectomy (level B evidence). It is important to note that the limited resection arm included anatomical segmentectomies as well as non-anatomical wedge resections, and tumours up to $3 \mathrm{~cm}$ were eligible.

Since this study, there has not been another published prospective trial on this topic. Several single centre retrospective studies have been published with conflicting conclusions [21, 22]. LANDrenEau et al. [23] performed a propensity-matched comparison between anatomical segmentectomy versus lobectomy for clinical stage I NSCLC. The study reported no significant difference in locoregional recurrence $(\mathrm{p}=1.00)$ or in 5-year disease-free survival (DFS) $(\mathrm{p}=0.47)$. YANO et al. [24] published a multi-institutional retrospective study $(\mathrm{n}=1737)$ on limited resections (segmentectomy or wedge resection) for cT1 N0 M0 NSCLC. Computed tomography imaging was used to determine the invasive potential of the tumour on the basis of the ratio of consolidation $(\mathrm{C})$ to the maximal tumour diameter $(\mathrm{T})(\mathrm{C} / \mathrm{T}$ ratio). Tumours were classified "invasive" if the $\mathrm{C} / \mathrm{T}$ ratio was $>0.25$ and "non-invasive" if $\mathrm{C} / \mathrm{T} \leqslant 0.25$. Overall survival and DFS after limited resection were $94.0 \%$ and $91.1 \%$ at 5 years, respectively. $\mathrm{C} / \mathrm{T} \leqslant 0.25$ predicted for good outcome, especially in cT1a N0 M0 disease. In a meta-analysis by CAO et al. [25] data were reviewed of intentional SLRs versus lobectomy for early stage NSCLC. Patients who underwent SLR for small, peripheral NSCLC after intentional selection rather than ineligibility for larger resections, achieved similar long-term survival outcomes as those who underwent lobectomies (level $\mathrm{C}$ evidence). However, patients included in this meta-analysis were a highly selected cohort and these results should be interpreted with caution. Two large prospective trials are currently ongoing (CALGB 140503 and JCOG0802/WJOG4607L), comparing segmentectomy versus lobectomy in NSCLC and the results are eagerly awaited (table 4) [26, 27].

SLR is a valid alternative to lobectomy in lung cancer patients who meet the following criteria: stage IA disease, tumours up to $2 \mathrm{~cm}$ in diameter, peripheral tumour location and predominantly ground-glass (non-solid) appearance on computed tomography imaging (level C evidence) [19]. Anatomical segmentectomy is preferred over wedge resection since the latter is associated with higher rates of locoregional recurrence in stage IA NSCLC $[28,29]$. Although, in case of a predominant ground glass opacity clinical stage IA adenocarcinoma, a wedge resection might be performed with a T1a tumour, and segmentectomy for a T1b tumour due to the low-grade malignancy and favourable prognosis (level C evidence) [30]. When dealing with a solid-type, clinical stage IA NSCLC, a lobectomy is recommended [31].

TABLE 4 Current randomised controlled trials comparing lobectomy versus sublobar resection

US CALGB 140503 trial (NCT00499330) [26]

Surgical study arm 1

Surgical study arm 2

Eligibility

Primary end-point Secondary end-points

Target recruitment

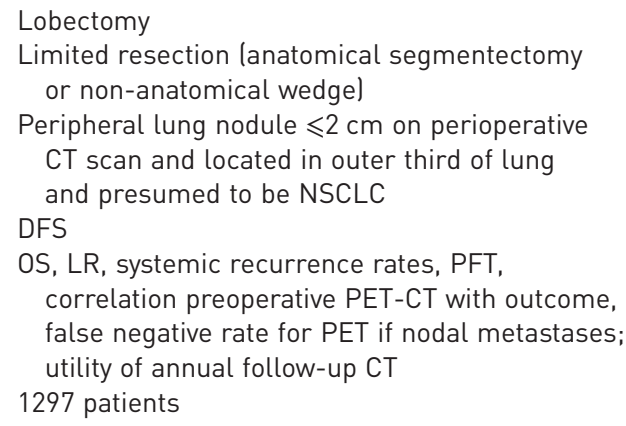

\section{Japanese trial (JCOG0802/WJOG4607L) [27]}

Lobectomy

Anatomical segmentectomy

Peripheral NSCLC (suspicion) $\leqslant 2 \mathrm{~cm}$ (proportion max. diameter of tumour to consolidation $>0.5$ )

OS

PFT, relapse-free survival, LR, proportion of completion of segmentectomy, LOS, duration chest tube, operation time, blood loss, number of auto-sutures

1100 patients

CT: computed tomography; NSCLC: nonsmall cell lung cancer; DFS: disease-free survival; OS: overall survival; LR: local recurrence; PFT: pulmonary function test; PET: positron emission tomography; LOS: length of stay in hospital. 
The second ESMO consensus conference on lung cancer concluded that SLR is acceptable for pure ground glass opacities and adenocarcinoma in situ with minimal invasion [15]. Lobectomy is still the preferred treatment for tumours $\leqslant 2 \mathrm{~cm}$ with solid appearance on computed tomography (level C evidence). Either open thoracotomy or VATS can be utilised as per experience of the thoracic surgeon.

Next to the aforementioned distal lung parenchyma saving procedures, proximal bronchoplastic interventions as sleeve resections may be the treatment of choice in early stage NSCLC with proximal bronchial involvement or positive N1 nodes around a lobar bronchus $[32,33]$. In this way, a pneumonectomy is avoided. Conservative resections are more often performed in carcinoids or in patients with impaired pulmonary reserve [34].

Minimally invasive surgery

MIT like VATS or RATS have been widely implemented as standard treatment for early stage NSCLC. Both procedures are equivalent in outcome (level C evidence) [35]. A retrospective analysis on the National Cancer Database (USA) looked at perioperative outcomes and survival of patients with clinical T1-2, N0 M0 NSCLC undergoing open or MIT: VATS and RATS [36]. This is an oncology database established by the American College of Surgeons and the American Cancer Society with data from hospital registries that are collected in more than 1500 Commission on Cancer-accredited facilities. Shorter median length of stay ( 5 versus 4 days; $\mathrm{p}<0.001$ ), and improved 2 -year survival ( $87 \%$ versus $86 \%$; $\mathrm{p}=0.04$ ) were observed when an MIT was used. There was no significant difference in nodal upstaging rates and 30-day mortality between the two groups. Comparing both MITs, there was no significant difference between VATS and RATS in regards to nodal upstaging, 30-day mortality and 2-year survival rates.

It is important to consider the role of nodal dissection, for which precise criteria have been established, to accurately stage the extent of cancer spread pathologically [37]. Medbery et al. [38] conducted a retrospective analysis on the same National Cancer Database and reported nodal upstaging was more frequent in patients treated with lobectomy by thoracotomy than by VATS $(12.8 \%$ versus $10.3 \%$; $\mathrm{p}<0.001)$. This difference was non-significant in patient groups treated in academic research facilities [38].

Differences in quality of life measures following open compared with VATS anatomical resection were assessed in a prospective study and were found to be similar in both patient groups (level C evidence) [39]. In addition the patient-reported physical component summary and pain scores after thoracotomy and VATS were also similar in both groups during the first 12 months after surgery [39].

\section{Radiotherapy}

Introduction

In addition to the advances in surgery over recent years, there have been dramatic developments in radiotherapy for NSCLC patients. Radiotherapy is established as an alternative curative treatment option for patients with early stage disease, particularly in patients who are considered medically inoperable due to co-morbidities. In this section, we compare local ablative therapies for stage I NSCLC and discuss the role of radiotherapy in a multidisciplinary setting as adjuvant and definitive treatment for stage I and II NSCLC.

Comparison of local ablative treatments for stage I NSCLC

Whenever there is a contraindication for surgery, radiotherapy may offer a valid alternative. To date, no valid prospective randomised controlled trial (RCT), comparing surgery and SBRT in medically operable patients with early stage NSCLC, has been completed; therefore, the question of whether SBRT yields similar results as complete surgical resection, remains unanswered (level C evidence) [40]. A recently performed propensity matched comparison between surgery and SBRT in over 117000 patients with stage I NSCLC, derived from the National Cancer Database demonstrated that, although 95\% of patients received surgery, the median overall survival favoured the surgical group (62.3 versus 33.1 months; $\mathrm{p}<0.001)$ [40]. The main limitation of such analysis is the difficulty in attributing improved outcome to patient selection or better cancer control, particularly since causes of death are unknown. Unfortunately, prospective RCTs, comparing surgery and SBRT in medically operable patients with early stage NSCLC, have all been terminated prematurely due to poor accrual (table 5).

A recent combined analysis of patients randomised in both the Dutch ROSEL trial and the US STARS trial comparing SBRT with lobectomy demonstrated a significant 3-year overall survival advantage in favour of SBRT (95\% versus $79 \%$; $=0.037$ ) in the 58 included patients [41]. DFS was similar in both groups; however, severe grade 3 or more toxicity was lower in the SBRT group (10\% versus $44 \%$ ). Despite small numbers the data suggest "at least clinical equipoise between the two treatment modalities" (level B evidence). However, as discussed in several letters to the Editor, it should be noted that mortality in the surgical arm was unacceptably high, that histology was not obtained in every case and that direct comparison of locoregional control between surgery and radiotherapy is not possible [43-49]. Further interest lies in comparing SBRT to surgical resection (lobectomy or SLR) in patients considered 
TABLE 5 Completed randomised controlled trials comparing SBRT versus surgery

$\begin{array}{lcc}\begin{array}{l}\text { Dutch ROSEL trial } \\ \text { (NCT00687986) [41] }\end{array} & \text { US STARS trial } \\ \text { (NCTO0840749) [41] } & \text { (NCT01336894) [42] }\end{array}$

\begin{tabular}{|c|c|c|c|}
\hline Surgical study arm & $\begin{array}{l}\text { Anatomical resection with lymph node } \\
\text { dissection }\end{array}$ & Anatomical resection & SLR \pm brachytherapy \\
\hline SBRT study arm & $\begin{array}{l}60 \mathrm{~Gy} \text { in three fractions or } 60 \mathrm{~Gy} \text { in five } \\
\text { fractions }\end{array}$ & $\begin{array}{l}60 \mathrm{~Gy} \text { in three fractions or } 60 \mathrm{~Gy} \text { in } \\
\text { four fractions }\end{array}$ & Variable dose in three fractions \\
\hline Eligibility & Operable patients, stage IA disease & $\begin{array}{l}\text { Operable patients, stage IA \& IB } \\
\text { disease } \leqslant 4 \mathrm{~cm}\end{array}$ & $\begin{array}{l}\text { “High operable risk" patients, } \\
\text { stage IA disease }\end{array}$ \\
\hline Primary end-point & 5 year local control & 3 year OS & 5 year OS \\
\hline Secondary end-points & Toxicity, OS, quality adjusted life years & $\begin{array}{l}\text { Toxicity, progression-free, } \\
\text { disease-specific survival }\end{array}$ & Toxicity, DFS \\
\hline Recruitment & 22 patients & 36 patients & 13 patients \\
\hline
\end{tabular}

SBRT: stereotactic body radiotherapy; OS: overall survival; SLR: sub-lobar resection; DFS: disease-free survival.

\begin{abstract}
"high-risk" for surgery. There are ongoing studies, assessing randomisation in this setting, currently recruiting (table 6).

The use of radiofrequency ablation (RFA) might rival with SBRT or SLR in early stage NSCLC. One study has compared the selection criteria and short-term outcomes in three prospective clinical trials that used SBRT (Radiation Therapy Oncology Group (RTOG) trial 0236), SLR (American College of Surgeons Oncology Group (ACOSOG) trial Z4032) and RFA (ACOSOG trial Z4033) [50]. The overall 90-day mortality for SBRT, surgery and RFA was $0 \%, 2.4 \%$ and $2.0 \%$, respectively ( $\mathrm{p}=0.5$ ) (level $\mathrm{C}$ evidence). The RFA trial included older patients with more impaired lung function. Another study has assessed the outcomes of SLR, RFA and radiation treatment in 116 patients with histologically proven stage I NSCLC from a prospective database [51]. The hazard ratio for primary tumour recurrence adjusted for age and tumour size was 2.73 (95\% CI 0.72-10.27) for SLR versus radiotherapy and 7.57 (95\% CI 1.94-29.47) for SLR versus RFA. SLR was associated with a higher primary tumour control rate compared with RFA or radiotherapy but no differences were observed in overall survival or DFS (level C evidence). Interpretation of data from both these studies is limited as baseline patient characteristics were not comparable and treatment was not randomly assigned. In particular in the second study the radiotherapy group included patients treated with both SBRT (57\%) and conventionally fractionated radiotherapy (43\%). The median tumour size was significantly larger in the radiotherapy group compared with the other two groups. A large prospective RCT is required to assess the benefits of RFA in comparison with SBRT and surgery.
\end{abstract}

Adjuvant radiotherapy in resected early stage NSCLC

A meta-analysis of data from nine randomised trials of adjuvant radiotherapy after resection of stage I-III NSCLC revealed a significant absolute detriment of $7 \%$ increased mortality at 2 years with the addition of

TABLE 6 Planned/ongoing randomised controlled trials comparing SBRT versus surgery

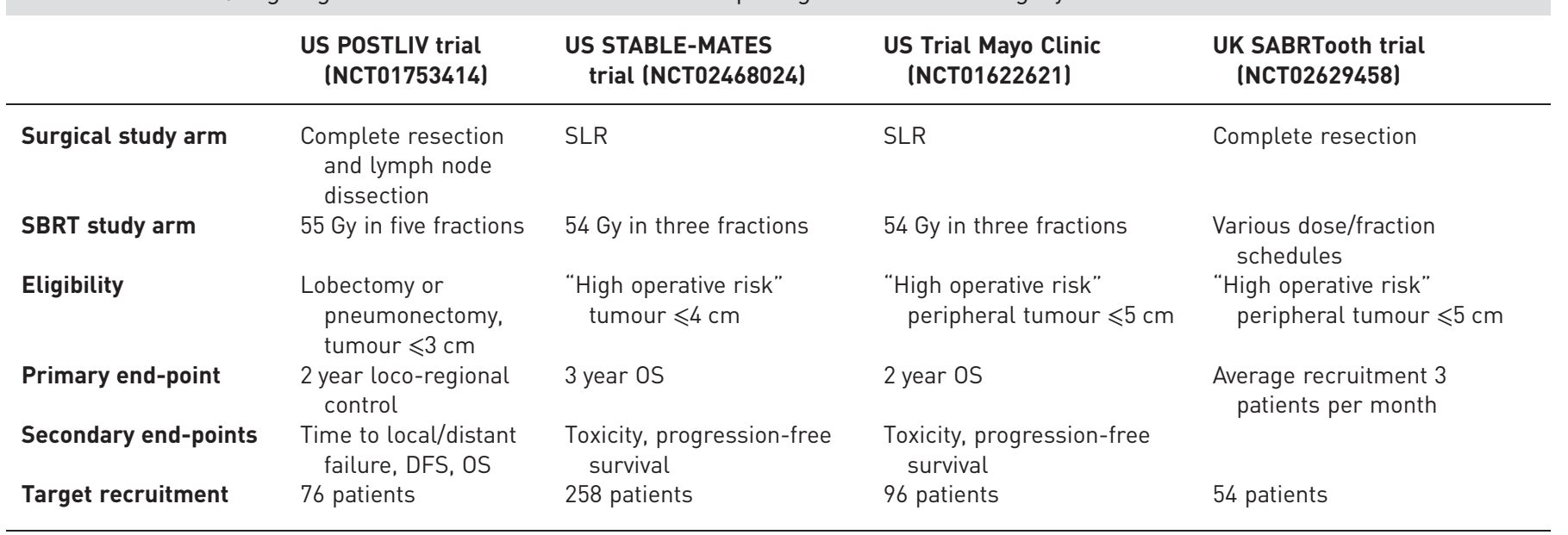

SBRT: stereotactic body radiotherapy; SLR: sublobar resection; OS: overall survival; DFS: disease-free survival. 
radiotherapy (level A evidence) [52]. Subgroup analyses suggested that the adverse effect was greatest for patients with stage I and II disease and therefore adjuvant radiotherapy is not recommended for completely resected early stage disease $[15,53]$.

\section{Definitive radiotherapy for stage I NSCLC}

SBRT makes use of advanced radiotherapy planning and delivery techniques to permit high doses of radiation per fraction to be given accurately to small discrete targets with high conformality and rapid dose fall-off within the surrounding normal tissues. The majority of published studies of lung SBRT are single-centre retrospective series (level $\mathrm{C}$ evidence). There are technical variations in practice in the literature including whether the reported radiation dose is prescribed to the $100 \%$ or to the isodose covering the target, in the type of planning algorithms software and whether a heterogeneity correction was applied. Additionally, there are variations in patient selection, including whether there was pathological confirmation of the treated lesion, staging, including whether the mediastinum was invasively staged and in the computed tomography scanning follow-up intervals for assessment of local disease control. Bearing these limitations in mind, promising outcomes are observed with SBRT; for example, a systematic review of published studies of SBRT for peripherally positioned stage I NSCLC reports 2-year local disease control rates of $91 \%$ and 2-year overall survival rates of $70 \%$ (level C evidence) [54].

Importantly, it is the position of the steep dose fall off within normal tissues that determines the potential toxicity. While toxicity with lung SBRT is generally low with grade 3 or higher rates usually $<4 \%$ [55-57], the exception is for centrally placed lesions as highlighted in a single centre phase II study. Patients with centrally located tumours were treated with a schedule of 60-66 Gy in three fractions (54 Gy in three fractions equivalent with heterogeneity correction) and after 4 years follow-up had an 11-fold higher risk of developing grade 3-5 toxicities when compared with patients with peripherally located tumours [58]. This led to the initial definition of the "no fly zone" (the volume encompassing $2 \mathrm{~cm}$ in all directions around the proximal bronchial tree) used in the RTOG 0236 trial [57] and subsequent SBRT studies (level C evidence).

Various dose fractionation schedules are reported in the literature varying between one and 10 fractions with higher number of fractions predominantly being used for more centrally located lesions; however, the optimal dose remains unknown and is complicated by the variation in dose prescription methods used in the literature, making comparison of outcomes challenging (level $\mathrm{C}$ evidence). While schedules with a biologically equivalent dose (BED) of $100 \mathrm{~Gy} 10$ or more are associated with high local disease control rates $[59,60]$, a meta-analysis suggests the highest biologically equivalent schedules (>146 Gy10) may be associated with lower survival rates than the medium-high schedules (106-146 Gy10) (level C evidence) [61].

To address the dose question for peripheral tumours, the randomised phase II RTOG 0915 trial compared $48 \mathrm{~Gy}$ in four fractions (BED $105 \mathrm{Gy10}$ ) to a single $34 \mathrm{~Gy}$ fraction (BED $150 \mathrm{Gy10}$ ) [62]. One-year overall survival was $85 \%$ in the single-fraction arm and $91 \%$ in the four-fraction arm with similar toxicity and local tumour control rates (level B evidence). Further follow-up is awaited to decide whether the single-fraction schedule will be compared to the RTOG 0236 schedule of $54 \mathrm{~Gy}$ in three fractions in a phase III setting for peripheral lesions. For central lesions, the initial results from the RTOG 0813 study investigating maximum tolerated dose for central lesions using five fractions, presented in abstract form, suggest that the highest investigated dose level of $60 \mathrm{~Gy}$ in five fractions is associated with a $7.2 \%$ risk of severe dose limiting toxicity [63]. Data on efficacy of the various dose levels in the phase II component of the study are awaited prior to decision about the dose to be considered in a phase III setting [63]. The European Organisation for Research and Treatment of Cancer (EORTC) LungTech trial (NCT01795521) investigating the safety of 60 Gy in eight fractions for centrally lesions is actively recruiting. When comparing studies with treatment of central lesions it is also important to note that there is more than one definition of a "central" lesion in the literature [64].

For inoperable patients, in comparison with standard fractionation radiotherapy, the Scandinavian phase II SPACE RCT compared 3D conformal radiotherapy with 70 Gy in 7 weeks with SBRT to 66 Gy in three fractions in inoperable patients with stage I peripheral lesions. Initial results, in abstract form, with a median follow up of 37 months reveal no significant difference in DFS or overall survival (level B evidence) [65]. However, the patients in the SBRT arm experienced significantly less any-grade pneumonitis (19\% versus 36\%) and oesophagitis (8\% versus 30\%) with improved dyspnoea, cough and chest pain quality-of-life measures. The phase III RTOG 0902 CHISEL trial (NCT01014130) completed recruitment and the results are awaited. There has been no direct comparison between SBRT and RFA in inoperable patients with early stage NSCLC; however, due to the greater body of evidence in the literature to support SBRT as definitive treatment for NSCLC, SBRT is considered the most appropriate therapy for inoperable patients with stage I NSCLC (level C evidence).

Despite SBRT being well tolerated, patient selection remains important. The majority of published SBRT trials included lesions up to $5 \mathrm{~cm}$ in diameter. Larger lesions are included in multiple retrospective series 
and can be considered for SBRT if dose constraints to surrounding normal tissues can be met. Alternative more protracted schedules can also be considered, for example $60 \mathrm{~Gy}$ in 15 fractions [66] or 70 Gy in 17 fractions [67]. As for medically inoperable patients with poor lung function and multiple co-morbidities and advanced age, SBRT needs to be weighed up against the risks of no treatment. The median survival of patients with routinely detected clinical stage I and II disease is approximately 10 months [68], and population-based studies of elderly patients with early stage NSCLC suggest that the observed improvement in overall survival over time is limited to patients treated with radiotherapy, including SBRT, rather than surgery or to those not treated radically (level $\mathrm{C}$ evidence) [69]. Therefore, advanced age alone should not exclude patients from SBRT. With co-morbidities, there are no absolute contraindications to SBRT and, in general, patients with ECOG performance status of $0-2$ or poor lung function [70, 71] should be considered for treatment. An important relative contraindication to SBRT, however, is active interstitial lung disease with higher than expected reported cases of severe or fatal pneumonitis in retrospective series $[72,73]$.

Up to $20 \%$ of patients treated with SBRT will relapse with distant metastases after treatment $[74,75]$. There is no proven role for adjuvant chemotherapy following SBRT particularly in patients with larger lesions $(\geqslant 4 \mathrm{~cm})$ that would be considered for adjuvant therapy following resection. A study in this patient population would be interesting. However, given the majority of these patients are considered medically inoperable, many may not be suitable candidates for platinum-based systemic therapy.

In summary, SBRT is the standard of care for medically inoperable patients with early stage peripheral NSCLC $[15,16]$. In comparison with surgery in operable patients, SBRT remains an alternative and offers at least clinical equipoise with surgery, especially in those considered "high risk" for surgery until further evidence is available comparing the two modalities. Prospective trial data are awaited to determine the optimal dose schedules, in particular for central lesions $[15,76]$.

\section{Definitive (chemo)radiotherapy for stage II NSCLC}

For the relatively small proportion of patients with medically inoperable stage II NSCLC not suitable for SBRT, usually because of ipsilateral hilar nodal involvement, the standard of care is treatment with chemo-radiotherapy (CRT) using conventional fractionation and platinum-based regimens [77-79]. The role of concomitant compared with sequential chemotherapy in this patient group is less clear. In the landmark meta-analysis of over 1200 patients with stage I-III disease, concomitant CRT was associated with a $4.5 \%$ benefit in overall survival at 5 years compared with a sequential approach at the expense of a significant increase in acute oesophageal toxicity from $4 \%$ to $18 \%$ [80]. However, less than $3 \%$ of the patients included in the analysis had stage I-II with the vast majority having stage III disease (level B evidence). The added benefit of accelerated radiotherapy in the sequential setting is also less clear in stage II disease (level C evidence). The large meta-analysis assessing accelerated hypo- or hyper-fractionated radiotherapy schedules compared to conventionally fractionated treatment in over 2000 patients with NSCLC [81] demonstrated that accelerated schedules were associated with a $2.5 \%$ improvement in overall survival at 5 years. However, again only a small proportion of included patients, $<20 \%$, had stage I-II disease (level C evidence). Given the paucity of data on definitive CRT specifically in inoperable patients with stage II disease, a population-based outcomes study ( $>550$ patients) was recently performed in this patient group [82]. Stage II NSCLC patients treated with concomitant or sequential CRT were included and a median overall survival of 20.5 months was found. This figure approximates to survival figures in stage III disease from historic phase III trials (level C evidence). There is likely to be adverse selection bias for these patients with stage II disease given they were considered medically inoperable.

In summary, patients with inoperable stage II disease should be treated with definitive radiotherapy and consideration of the addition of chemotherapy concomitantly or sequentially should be given based on fitness to tolerate treatment. Further studies are required to assess the benefits of CRT in this population specifically. Additionally, the role of treatment dose intensification with isotoxic radiotherapy schedules [83], oncogene targeted systemic therapies, DNA damage repair and immune checkpoint inhibitors needs to be explored.

Salvage surgery after stereotactic radiotherapy

For recurrent or persistent NSCLC after SBRT, salvage surgery is a valid therapeutic option when a complete resection is feasible and cardiopulmonary functional assessment shows no contra-indication for the anticipated resection. Although surgical salvage is a relatively new concept in thoracic surgery, recent data show that it is feasible in selected patients, not only for NSCLC but also for lung metastases (level E evidence) $[49,84]$. Technical difficulties in performing the resection are limited on the condition that the hilum and mediastinum are not irradiated beforehand. More long-term data are needed to determine its role more precisely. 


\section{Systemic therapy \\ Introduction}

In contrast to the previous sections (locoregional treatment), in this section systemic therapy is reviewed. Platinum-based chemotherapy, targeted agents, immunotherapy and anti-angiogenic agents as adjuvant therapies for resected early stage NSCLC are discussed.

\section{Adjuvant platinum-based chemotherapy}

The RCTs of adjuvant cisplatin-based chemotherapy versus observation in patients with resected stage I-III NSCLC demonstrate statistically significant benefit for the addition of systemic therapy (level A evidence) [85-89]. An overview of these trials is provided in table 7. A meta-analysis of pooled data $(n=4584)$ revealed a $5.3 \%$ (overall survival) and 5.2\% (DFS) improvement at 5 years with the addition of cisplatin-based chemotherapy [90]. However, a statistically significant interaction between disease stage and chemotherapy effect was observed. In stage IA, a potential detrimental effect was found with the addition of chemotherapy. In stage IB, a trend was seen favouring the addition of systemic therapy (level B evidence). A subsequent study of adjuvant carboplatin/paclitaxel in patients with resected stage IB NSCLC demonstrated no overall survival benefit; however, an unplanned retrospective subgroup analysis revealed a benefit for patients with tumours $\geqslant 4 \mathrm{~cm}$ [91]. Therefore, the ESMO guidelines state that adjuvant chemotherapy can be considered for the latter [15]. As mentioned previously, in the forthcoming eighth TNM edition, it is proposed to reclassify tumours $\geqslant 4 \mathrm{~cm}$ as $\mathrm{T} 2 \mathrm{~b}[6]$ and, subsequently, these are grouped as stage IIA instead of stage IB [7].

Recently, a Cochrane meta-analysis on adjuvant chemotherapy (without radiotherapy) in resected NSCLC was performed: 35 trials were identified and an analysis based on 8447 participants showed a clear benefit of adjuvant chemotherapy (HR 0.86, 95\% CI 0.81-0.92; p<0.0001) with a 5-year absolute survival benefit of 4\% (level A evidence) [92]. The most studied adjuvant drug combination is cisplatin/vinorelbine, although the Cochrane meta-analysis showed little variation in effect between different regimens (level A evidence). Moreover, an exploratory analysis of the $\mathrm{E} 1505$ trial (adjuvant chemotherapy \pm bevacizumab in early stage resected NSCLC) presented at the American Society of Clinical Oncology (ASCO) 2016 annual conference showed no difference in DFS or overall survival for the four different cisplatin-based chemotherapy regimens (cisplatin with investigator's choice: vinorelbine, docetaxel, gemcitabin or pemetrexed) [93].

No difference in survival has been demonstrated between neoadjuvant and adjuvant treatment (level B evidence) [94, 95]. Due to adjuvant trial results, most neoadjuvant trials were closed prematurely [95]. A potential advantage of neoadjuvant chemotherapy is that compliance may be better. Due to their clinical condition, more patients are likely to complete four cycles of neoadjuvant chemotherapy, compared with the 50-70\% completing four treatment cycles demonstrated in most adjuvant studies [95, 97].

TABLE 7 Completed randomised, placebo controlled trials on (neo) adjuvant chemotherapy

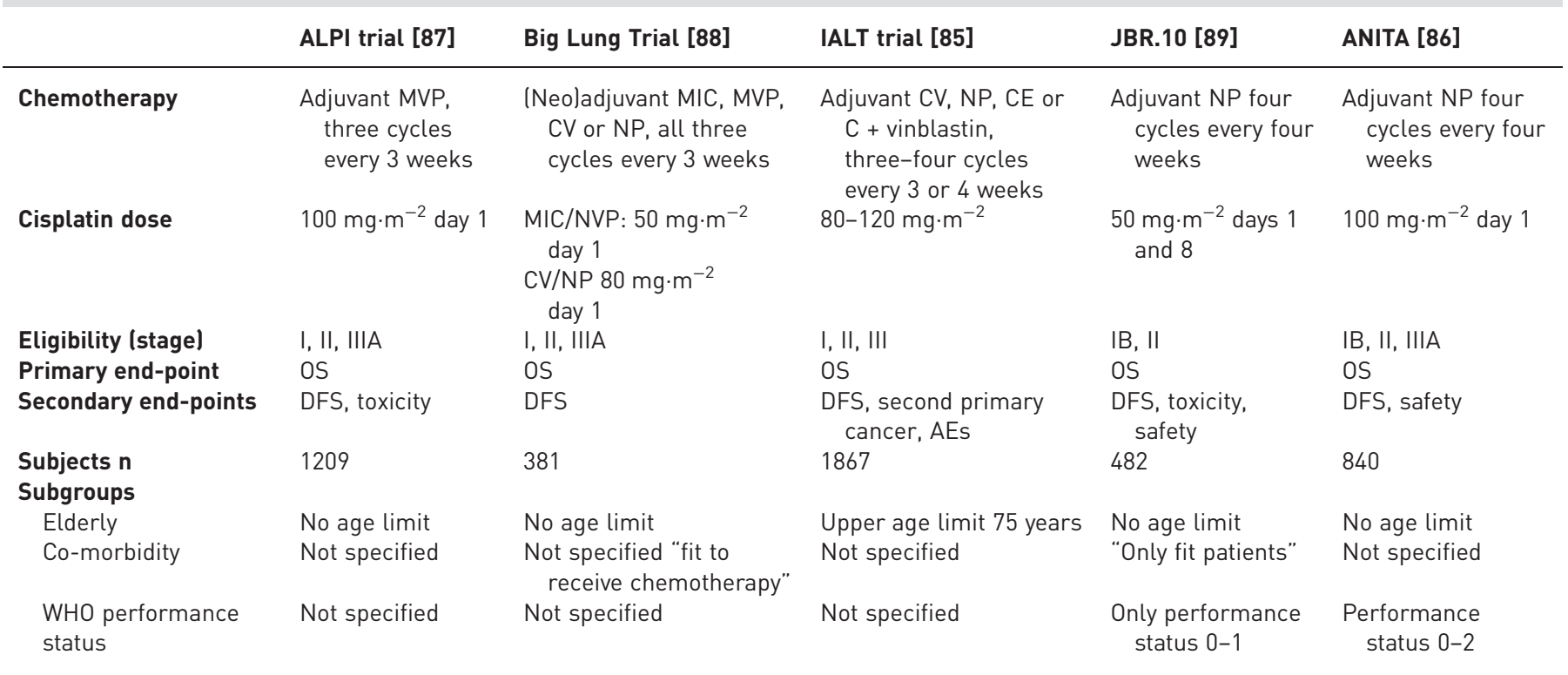

WHO: World Health Organization; MVP: mitomycin, vindesine, cisplatin; MIC: cisplatin, mitomycin, ifosfamide; CV: cisplatin, vindesine; NP: cisplatin, vinorelbin; CE: cisplatin, etoposide; C: cisplatin; OS: overall survival; DFS: disease-free survival; AE: adverse events. 
Patients enrolled in clinical trials are highly selected and often younger, with good performance status and fewer co-morbidities compared with patients in the general population. In a retrospective analysis of the Ontario Cancer Registry, it was shown that adjuvant chemotherapy had a detrimental effect in patients with severe co-morbidities (Charlson score 3+) [98]. A subgroup analysis of the JBR 10 study demonstrated that elderly ( $>65$ years) had the same amount of benefit with adjuvant chemotherapy than younger patients, without additional toxicity [99]. In the Lung Adjuvant Cisplatin Evaluation (LACE) meta-analysis the same was true for patients aged $>70$ years [100]. Interestingly, in both studies the elderly received on average fewer chemotherapy cycles and reduced cisplatin dose. Improved overall survival was noted for elderly (age $>65$ years) with stage I (tumour $\geqslant 4 \mathrm{~cm}$ ) in a Surveillance, Epidemiology and End Results (SEER) -Medicare analysis $(n=3289)$ although adjuvant chemotherapy was associated with an increased number of serious adverse events [101]. However, data on patients aged $>75$ years are lacking as this group was under-represented in clinical trials (level B evidence). In clinical trials, adjuvant chemotherapy is started within $6-8$ weeks of surgery. In daily practice, $35 \%$ of patients start adjuvant chemotherapy $>10$ weeks after surgery; however, this did not appear to have a negative impact on survival [98].

The meta-analysis showed a clear overall survival benefit for adjuvant chemotherapy and it is advised in all current guidelines [100]. However, tools to optimally select patients who benefit from chemotherapy are warranted, especially since the updated survival analysis of the International Adjuvant Lung Cancer Trial (IALT) showed that the survival benefit did not persist after 5 years of follow-up, mainly due to increased non-lung cancer mortality in patients treated with adjuvant chemotherapy (level B evidence) [102]. The histological NSCLC subtype has not been shown to be a predictive factor of benefit from adjuvant chemotherapy and, as yet, there is no fully validated biomarker to identify patient subgroups who may derive particular benefit [92]. The IALT biomarker group has studied predictive value of several biomarkers including excision repair cross-complementation group 1 (ERCC1) and P53. ERCC1 expression seemed to be a predictive marker for response to platinum-based chemotherapy, with only ERCC1-negative tumours benefitting from adjuvant chemotherapy [103]. Although the randomised adjuvant Tailored Postsurgical Therapy in Early Stage NSCLC (TASTE) trial showed that a biology-driven randomised adjuvant trial is feasible, the planned phase III trial was terminated due to inaccuracy of the ERCC immunohistochemical staining classification [104]. Until now, no potential predictive biomarker has been validated in an RCT and none can be used to select patients who benefit from adjuvant chemotherapy. Invasive components of the tumour (vascular, lymphatic or perineural invasion) are also of prognostic significance in early stage NSCLC. Although not evaluated in RCTs, it is possible that resected early stage patients with adverse prognostic factors would benefit more from adjuvant treatment than those without. In a meta-analysis (22 studies, a total of 25280 patients with resected stage I NSCLC), visceral pleural invasion was associated with death (HR 1.427, 95\% CI 1.221-1.669; $\mathrm{p}<0.001$ ) and recurrence (HR 1.600, 95\% CI 1.284-1.995; $\mathrm{p}<0.001$ ) [105]. This increased risk was found for all subgroups including patients with tumours $<2 \mathrm{~cm}$.

Comparable results were found in another analysis including 13 cohort studies (27171 patients) (level C evidence) [106]. Lymphovascular invasion (LVI) was also associated with a worse prognosis in a recent meta-analysis including resected stage I patients (20 studies, 8032 patients) [107]. Risk of death was significantly higher in patients with LVI (HR 1.81, 95\% CI 1.53-2.14) (level C evidence). Conflicting studies exist on the prognostic significance of perineural invasion [108, 109]. A newer method to evaluate prognosis is the use of an immunoscore. For example, it has been shown that stromal CD8 ${ }^{+}$ tumour-infiltrating lymphocytes density had a prognostic impact across all stages in multivariate analysis in a study including 797 resected stage I-IIIA NSCLC patients [110]. 5-year overall survival was $61 \%, 50 \%$ and $41 \%$ for $\mathrm{CD}^{+}$high, intermediate and low scores, respectively $(\mathrm{p}<0.001)$ (level C evidence).

\section{Adjuvant targeted agents}

The effect of adjuvant epidermal growth factor receptor (EGFR) tyrosine kinase inhibitor (TKI) was tested in the BR19 study [111]. Unselected patients with completely resected stage IB-IIIA NSCLC were randomised between gefitinib or placebo for 2 years. This study was closed prematurely; however, it showed no benefit for adjuvant gefitinib (level B evidence) [111]. In addition, no benefit was shown in the subgroup with an activating EGFR mutation $(n=15)$. With the proven efficacy of EGFR-TKIs in mutation-positive advanced disease, the role of adjuvant erlotinib versus placebo has been explored in patients with completely resected EGFR-expressing (immunohistochemistry) or EGFR-amplified (fluorescence in situ hybrisation) stage IB to IIIA disease [112]. Adjuvant erlotinib for 2 years did not prolong DFS in the EGFR mutation-positive NSCLC. Although there was a trend to improved DFS with gefitinib in the EGFR-activating mutation positive subgroup ( $\mathrm{n}=161$, HR $0.6195 \%$ CI 0.38-0.98; $\mathrm{p}=0.039$ ), this was not statistically significant due to hierarchical testing (level B evidence). Discussion points are the dose and duration of treatment. It might be that, in line with results in breast cancer, the treatment period was too short. Currently, there is no role for TKIs in the adjuvant setting, but further research in the EGFR mutant positive patients is warranted and trials are ongoing (table 8). 
TABLE 8 Planned/ongoing phase III randomised controlled trials comparing adjuvant EGFR-TKI to placebo after complete resection in EGFR mutant lexon 19 deletion/exon 21 L858R) NSCLC patients

\begin{tabular}{|c|c|c|c|c|c|c|c|}
\hline & $\begin{array}{l}\text { ADJUVANT } \\
\text { (NCT } \\
\text { 01405079] }\end{array}$ & $\begin{array}{l}\text { International } \\
\text { ADAURA trial } \\
\text { (NCT 02511106) }\end{array}$ & $\begin{array}{l}\text { Korean trial } \\
\text { (NCT 02795884) }\end{array}$ & $\begin{array}{l}\text { Japanese } \\
\text { WJ0G6410L trial }\end{array}$ & $\begin{array}{l}\text { Chinese EVIDENCE } \\
\text { trial (NCT02448797) }\end{array}$ & $\begin{array}{l}\text { Chinese ICTAN trial } \\
\text { (NCT 01996098) }\end{array}$ & ICWIP (NCT 02125240) \\
\hline Experimental arm & $\begin{array}{l}\text { Gefitinib } 250 \mathrm{mg} \\
\text { once daily, } \\
24 \text { months }\end{array}$ & $\begin{array}{l}\text { Osimertinib } 80 / \\
40 \mathrm{mg} \text { once daily }\end{array}$ & $\begin{array}{l}\text { Intercalated: erlotinib } \\
150 \text { mg once daily } \\
\text { days } 8-21 \text {, } \\
\text { pemetrexed/cisplatin } \\
\text { day } 1, \text { four cycles } \\
\text { every three weeks; } \\
\text { maintenance: } \\
\text { erlotinib } 150 \mathrm{mg} \\
\text { once daily } 1 \text { year }\end{array}$ & $\begin{array}{l}\text { Gefitinib } 250 \mathrm{mg} \\
\text { once daily, } \\
24 \text { months }\end{array}$ & $\begin{array}{l}\text { Icotinib } 125 \mathrm{mg} \text { three } \\
\text { times daily until PD }\end{array}$ & $\begin{array}{l}\text { Arm A: icotinib } 125 \mathrm{mg} \\
\text { three times daily, } \\
6 \text { months; arm B: } \\
\text { icotinib } 125 \mathrm{mg} \text { three } \\
\text { times daily, } \\
12 \text { months }\end{array}$ & $\begin{array}{l}\text { Icotinib } 125 \mathrm{mg} \text { three } \\
\text { times daily until PD }\end{array}$ \\
\hline Comparator arm & $\begin{array}{l}\text { NP four cycles } \\
\text { every three } \\
\text { weeks }\end{array}$ & Placebo once daily & $\begin{array}{l}\text { NP four cycles every } \\
\text { three weeks }\end{array}$ & $\begin{array}{l}\text { NP four cycles } \\
\text { every three weeks }\end{array}$ & $\begin{array}{l}\text { NP four cycles every } 3 \\
\text { weeks }\end{array}$ & $\begin{array}{l}\text { Platinum-based } \\
\text { chemotherapy four } \\
\text { cycles }\end{array}$ & $\begin{array}{l}\text { Placebo three times } \\
\text { daily until PD }\end{array}$ \\
\hline Eligibility & Stage IIA-IIIA & $\begin{array}{l}\text { Stage IB-IIIA, } \\
\text { predominantly } \\
\text { non-squamous } \\
\text { cell carcinoma, } \\
\text { with/without } \\
\text { adjuvant } \\
\text { chemotherapy }\end{array}$ & $\begin{array}{l}\text { Stage IB-IIIA } \\
\text { non-squamous cell } \\
\text { carcinoma }\end{array}$ & Stage II-III & $\begin{array}{l}\text { Stage II-IIIA } \\
\text { adenocarcinoma, no } \\
\text { right } \\
\text { pneumonectomy }\end{array}$ & Stage IIA-IIIA & $\begin{array}{l}\text { Stage II-IIIA } \\
\text { adenocarcinoma, } \\
\text { adjuvant four cycles } \\
\text { cisplatin-based } \\
\text { chemotherapy }\end{array}$ \\
\hline Primary end-point & DFS & DFS & DFS & DFS & DFS & DFS & DFS \\
\hline Secondary end-points & $\begin{array}{l}\text { OS, 3-year DFS, } \\
\text { 5-year DFS } \\
\text { and OS, AEs, } \\
\text { QoL }\end{array}$ & $\begin{array}{l}\text { 2, } 3 \text { and 5-year DFS, } \\
\text { OS, HRQoL, } \\
\text { pharmacokinetics }\end{array}$ & OS, AEs & $\begin{array}{l}\text { OS, AEs, type of } \\
\text { recurrence }\end{array}$ & OS & OS, AEs, QoL & OS, AEs, HRQoL \\
\hline Target recruitment & 220 patients & 700 patients & 227 patients & 230 patients & 320 patients & 477 patients & 300 patients \\
\hline
\end{tabular}

EGFR: epidermal growth factor receptor; TKI: tyrosine kinase inhibitor; PD: progressive disease; NP; cisplatin, vinorelbine; DFS: disease-free survival; OS: overall survival; AEs: adverse events; QoL: quality of life; HRQoL: health-related quality of life. 
Adjuvant immunotherapy

Another promising adjuvant systemic therapy being investigated is immunotherapy. One of these approaches is targeting MAGE-A3. MAGE-A3 is expressed in 35\% of NSCLC patients. A phase II RCT showed that in patients with stage IB-II resected NSCLC expressing MAGE-A3 the HR for DFS was in favour of treatment with recombinant MAGE-A3 protein in combination with an immunostimulant; however, this was not statistically significant (HR 0.75, 95\% CI 0.46-1.23; p=0.248) [113]. In the phase III MAGRIT RCT, presented at ESMO 201413824 patients were screened for MAGE-A3 and 2270 were randomised between adjuvant MAGE-A3 immunotherapy or placebo. Unfortunately, MAGE-A3 immunotherapy did not improve outcome (level B evidence) [114]. The full paper has not been published yet.

Other interesting immunotherapy strategies currently being explored in several phase III RCTs are the use of checkpoint inhibitors. As these studies started enrolment in 2015, results are expected within a few years. An overview of these studies is provided in table 9.

\section{Adjuvant anti-angiogenic agents}

As angiogenesis is one of the hallmarks of cancer and important for growth and metastatic potential of tumours, the addition of bevacizumab to platinum-based chemotherapy was tested in a phase III RCT (E1505, n=1501) and presented at the World Lung Cancer Conference 2015 [93]. Patients with resected IB $(>4 \mathrm{~cm})$ to IIIA NSCLC were treated with four cycles of cisplatin with either vinorelbine, pemetrexed, docetaxel or gemcitabine, and randomised between addition of bevacizumab for 1 year or chemotherapy alone. At time of interim analysis (all patients randomised), no difference was observed in the primary endpoint overall survival (HR 0.99 (95\% CI 0.81-1.21; p=0.93)) (level B evidence) and in the secondary endpoint DFS (HR 0.98 (95\% CI 0.84-1.14; p=0.75)). As low molecular weight heparin may also improve outcome, it was tested in the NVALT-8 trial $(n=202)$ whether the addition of nadroparin to adjuvant chemotherapy (cisplatin combined with pemetrexed (non-squamous) or gemcitabine (squamous) improved DFS in resected stage I-IIIA NSCLC patients. Results were presented at the ASCO 2016 conference: no significant differences in DFS were found, which is different from the results in the abstract [115].

In summary, international guidelines recommend the use of adjuvant platinum-containing chemotherapy in patients with completely resected stage II disease and consideration of its use in patients with resected stage IB disease with a primary tumour $\geqslant 4 \mathrm{~cm}$. According to the proposed 8th TNM edition, these are all grouped in stage II $[15,53]$. Age is not a selection criterion per se, but co-existence of severe comorbidity may lead to detrimental outcome. Currently no predictive biomarkers of clinical benefit are available and new treatment strategies, such as EGFR-TKIs, angiogenesis inhibitors and immunomodulation have not yet resulted in improved outcome, but additional trials are ongoing.

TABLE 9 Planned/ongoing phase III randomised controlled trials comparing adjuvant immunotherapy to placebo after complete resection in NSCLC patients

\section{IMpower010 (NCT02486718) \\ ANVIL (NCT02595944) \\ EORTC-ETOP PEARLS trial (NCT02504372)}

$$
\begin{aligned}
& \text { Atezolizumab } 1200 \mathrm{mg} \\
& \text { intravenous } 16 \text { cycles } \\
& \text { every three weeks } \\
& \text { observation } \\
& \text { Stage IB ( } \geqslant 4 \mathrm{~cm})-I I I A \\
& \text { adjuvant cisplatin } \\
& \text { based chemotherapy }
\end{aligned}
$$

\section{Primary end-point} Secondary end-points

\section{DFS}

OS, AEs, pharmacokinetics, immunogenicity

Target recruitment

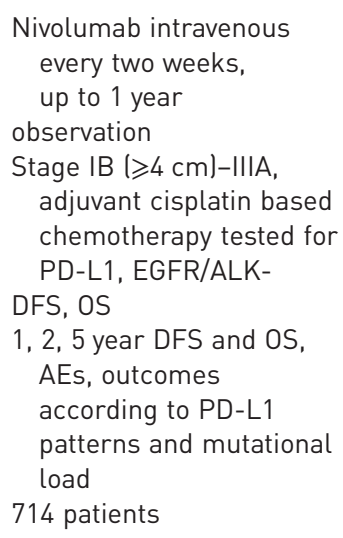

Nivolumab intravenous every two weeks, up to 1 year observation

Stage IB $(\geqslant 4 \mathrm{~cm})-I I I A$ adjuvant cisplatin based chemotherapy tested for PD-L1, EGFR/ALKDFS, OS

1, 2, 5 year DFS and OS, $A E s$, outcomes according to PD-L1 patterns and mutational load

714 patients

Canadian Cancer Trials Group (NCT02273375)

PD-L1: programmed death-ligand1; EGFR: epidermal growth factor receptor; ALK: anaplastic lymphoma kinase; DFS: disease-free survival; OS: overall survival; AEs: adverse events; LCSS: lung cancer specific survival. 
TABLE 10 Summary of treatment options for stage I-II NSCLC according to proposed 8th TNM classification

\begin{tabular}{llll} 
Clinical TN & Clinical stage & Medically operable & Medically inoperable \\
\hline T1almi) N0 & IA1 & SLR & SLR/SBRT/RFA \\
T1a N0 & IA1 & SLR/lobectomy & SLR/SBRT/RFA \\
T1b N0 & IA2 & SLR/lobectomy & SLR/SBRT/RFA \\
T1c N0 & IA3 & Lobectomy & SBRT/RFA \\
T2a N0 & IB & Lobectomy/sleeve & SBRT/Conventional EBRT \\
T2b N0 & IIA & Lobectomy/sleeve/pneumonectomy consider adjuvant chemotherapy & SBRT/Conventional EBRT \\
T1a-c N1 & IIB & Lobectomy - adjuvant chemotherapy & (Chemo)radiation \\
T2a-b N1 & IIB & Lobectomy - adjuvant chemotherapy & (Chemo)radiation \\
T3 N0 & IIB & Lobectomy/sleeve/pneumonectomy/extended resection consider & (Chemo)radiation \\
& & adjuvant chemotherapy &
\end{tabular}

TN: tumour-node staging; mi: minimally invasive; SLR: sublobar resection; RFA: radiofrequency ablation; EBRT: external beam radiotherapy; SBRT: stereotactic body radiotherapy.

\section{Conclusion: multidisciplinary integration}

Integration of the different treatment modalities in patients with early stage NSCLC remains quite a challenge for the practicing oncologist. For this reason, a thorough discussion within a MDT is required to determine the optimal diagnostic and treatment schedule for each individual patient. Although not always easy to define in daily practice, cardiopulmonary risk assessment is important to decide on the specific treatment or combination of therapeutic modalities that will be administered. Performance status, age, co-morbidities and patient preferences also need to be taken into account. Compromised patients will have to be treated less aggressively.

This review summarises the key evidence behind the multidisciplinary decision making for individual patients with early stage NSCLC with a summary of options provided in table 10. This multidisciplinary paper also highlights some of the grey areas where further research is needed and discusses ongoing clinical trials. Undoubtedly, further development of MIT and SBRT, newly introduced chemotherapeutic and targeted agents in combination with further advances in immunotherapy will provide a broad spectrum of therapeutic modalities. It is important to maintain clinical equipoise in presenting options to patients and to enrol patients in clinical trials where possible in order to better define the optimal treatment and improve outcomes for future patients with this disease.

\section{References}

$1 \quad$ National Lung Screening Trial Research T,Aberle DR, Adams AM, et al. Reduced lung-cancer mortality with low-dose computed tomographic screening. N Engl J Med 2011; 365: 395-409.

2 Janssen-Heijnen ML, Maas HA, Houterman S, et al. Comorbidity in older surgical cancer patients: influence on patient care and outcome. Eur J Cancer 2007; 43: 2179-2193.

3 Travis WD, Brambilla E, Nicholson AG, et al. The 2015 World Health Organization Classification of Lung Tumors: Impact of Genetic, Clinical and Radiologic Advances Since the 2004 Classification. J Thorac Oncol 2015; 10: $1243-1260$.

4 Travis WD, Brambilla E, Noguchi M, et al. International Association for the Study of Lung Cancer/American Thoracic Society/European Respiratory Society international multidisciplinary classification of lung adenocarcinoma. J Thorac Oncol 2011; 6: 244-285.

5 Van Schil PE, Asamura H, Rusch VW, et al. Surgical implications of the new IASLC/ATS/ERS adenocarcinoma classification. Eur Respir J 2012; 39: 478-486.

6 Rami-Porta R, Bolejack V, Crowley J, et al. The IASLC Lung Cancer Staging Project: Proposals for the Revisions of the T Descriptors in the Forthcoming Eighth Edition of the TNM Classification for Lung Cancer. $J$ Thorac Oncol 2015; 10: 990-1003.

7 Goldstraw P, Chansky K, Crowley J, et al. The IASLC Lung Cancer Staging Project: Proposals for Revision of the TNM Stage Groupings in the Forthcoming (Eighth) Edition of the TNM Classification for Lung Cancer. J Thorac Oncol 2016; 11: 39-51.

8 Rami-Porta R, Crowley JJ, Goldstraw P. The revised TNM staging system for lung cancer. Ann Thorac Cardiovasc Surg 2009; 15: 4-9.

9 De Waele M, Van Schil P. Limited resections in high-risk patients. Curr Opin Pulm Med 2015; 21: 309-313.

10 López-Encuentra A, García-Luján R, Rivas JJ, et al. Comparison between clinical and pathologic staging in 2,994 cases of lung cancer. Ann Thorac Surg 2005; 79: 974-979.

11 Schuchert MJ, Abbas G, Pennathur A, et al. Sublobar resection for early-stage lung cancer. Semin Thorac Cardiovasc Surg 2010; 22: 22-31.

12 Brunelli A, Charloux A, Bolliger CT, et al. ERS/ESTS clinical guidelines on fitness for radical therapy in lung cancer patients (surgery and chemo-radiotherapy). Eur Respir J 2009; 34: 17-41.

13 Brunelli A, Kim AW, Berger KI, et al. Physiologic evaluation of the patient with lung cancer being considered for resectional surgery: Diagnosis and management of lung cancer, 3rd ed: American College of Chest Physicians evidence-based clinical practice guidelines. Chest 2013; 143: 5 Suppl, e166S-e190S. 
14 Lim E, Baldwin D, Beckles M, et al. Guidelines on the radical management of patients with lung cancer. Thorax 2010; 65 Suppl 3: iii1-ii27.

15 Vansteenkiste J, Crinò L, Dooms C, et al. 2nd ESMO Consensus Conference on Lung Cancer: early-stage non-small-cell lung cancer consensus on diagnosis, treatment and follow-up. Ann Oncol 2014; 25: 1462-1474.

16 De Leyn P, Dooms C, Kuzdzal J, et al. Revised ESTS guidelines for preoperative mediastinal lymph node staging for non-small-cell lung cancer. Eur J Cardiothorac Surg 2014; 45: 787-798.

17 van den Berg LL, Klinkenberg TJ, Groen HJ, et al. Patterns of recurrence and survival after surgery or stereotactic radiotherapy for early stage NSCLC. J Thorac Oncol 2015; 10: 826-831.

18 Groome PA, Bolejack V, Crowley JJ, et al. The IASLC Lung Cancer Staging Project: validation of the proposals for revision of the $\mathrm{T}, \mathrm{N}$, and $\mathrm{M}$ descriptors and consequent stage groupings in the forthcoming (seventh) edition of the TNM classification of malignant tumours. J Thorac Oncol 2007; 2: 694-705.

19 Sihoe AD, Van Schil P. Non-small cell lung cancer: when to offer sublobar resection. Lung Cancer 2014; 86: 115-120.

20 Ginsberg RJ, Rubinstein LV. Randomized trial of lobectomy versus limited resection for T1 N0 non-small cell lung cancer. Lung Cancer Study Group. Ann Thorac Surg 1995; 60: 615-622.

21 Fan J, Wang L, Jiang GN, et al. Sublobectomy versus lobectomy for stage I non-small-cell lung cancer, a meta-analysis of published studies. Ann Surg Oncol 2012; 19: 661-668.

22 Altorki NK, Yip R, Hanaoka T, et al. Sublobar resection is equivalent to lobectomy for clinical stage 1A lung cancer in solid nodules. J Thorac Cardiovasc Surg 2014; 147: 754-762.

23 Landreneau RJ, Normolle DP, Christie NA, et al. Recurrence and survival outcomes after anatomic segmentectomy versus lobectomy for clinical stage I non-small-cell lung cancer: a propensity-matched analysis. J Clin Oncol 2014; 32: 2449-2455.

24 Yano M, Yoshida J, Koike T, et al. Survival of 1737 lobectomy-tolerable patients who underwent limited resection for cStage IA non-small-cell lung cancer. Eur J Cardiothorac Surg 2015; 47: 135-142.

25 Cao C, Gupta S, Chandrakumar D, et al. Meta-analysis of intentional sublobar resections versus lobectomy for early stage non-small cell lung cancer. Ann Cardiothorac Surg 2014; 3: 134-141.

26 Blasberg JD, Pass HI, Donington JS. Sublobar resection: a movement from the Lung Cancer Study Group. J Thorac Oncol 2010; 5: 1583-1593.

27 Nakamura K, Saji H, Nakajima R, et al. A phase III randomized trial of lobectomy versus limited resection for small-sized peripheral non-small cell lung cancer (JCOG0802/WJOG4607L). Jpn J Clin Oncol 2010; 40: 271-274.

28 Smith CB, Swanson SJ, Mhango G, et al. Survival after segmentectomy and wedge resection in stage I non-small-cell lung cancer. J Thorac Oncol 2013; 8: 73-78.

29 Koike T, Koike T, Yoshiya K, et al. Risk factor analysis of locoregional recurrence after sublobar resection in patients with clinical stage IA non-small cell lung cancer. J Thorac Cardiovasc Surg 2013; 146: 372-378.

30 Tsutani Y, Miyata Y, Nakayama H, et al. Appropriate sublobar resection choice for ground glass opacity-dominant clinical stage IA lung adenocarcinoma: wedge resection or segmentectomy. Chest 2014; 145: 66-71.

31 Jeon HW, Kim YD, Kim KS, et al. Sublobar resection versus lobectomy in solid-type, clinical stage IA, non-small cell lung cancer. World J Surg Oncol 2014; 12: 215.

32 Tronc F, Grégoire J, Rouleau J, et al. Long-term results of sleeve lobectomy for lung cancer. Eur J Cardiothorac Surg 2000; 17: 550-556.

33 Van Schil PE, Brutel de la Riviere A, Knaepen PJ, et al. Long-term survival after bronchial sleeve resection: univariate and multivariate analyses. Ann Thorac Surg 1996; 61: 1087-1091.

34 Rizzardi G, Marulli G, Bortolotti L, et al. Sleeve resections and bronchoplastic procedures in typical central carcinoid tumours. Thorac Cardiovasc Surg 2008; 56: 42-45.

35 Louie BE, Wilson JL, Kim S, et al. Comparison of video-assisted thoracoscopic surgery and robotic approaches for clinical stage I and stage II non-small cell lung cancer using the Society of Thoracic Surgeons database. Ann Thorac Surg. 201; May 18 (Epub) doi: 10.1016/j.athoracsur.2016.03.032.

36 Yang CF, Sun Z, Speicher PJ, et al. Use and outcomes of minimally invasive lobectomy for stage i non-small cell lung cancer in the National Cancer Data base. Ann Thorac Surg 2016; 101: 1037-1042.

37 Rami-Porta R, Wittekind C, Goldstraw P, International Association for the Study of Lung Cancer Staging C. Complete resection in lung cancer surgery: proposed definition. Lung Cancer 2005; 49: 25-33.

38 Medbery RL, Gillespie TW, Liu Y, et al. Nodal upstaging is more common with thoracotomy than with VATS during lobectomy for early-stage lung cancer: an analysis from the National Cancer Data Base. J Thorac Oncol 2016; 11: 222-233.

39 Rizk NP, Ghanie A, Hsu M, et al. A prospective trial comparing pain and quality of life measures after anatomic lung resection using thoracoscopy or thoracotomy. Ann Thorac Surg 2014; 98: 1160-1166.

40 Puri V, Crabtree TD, Bell JM, et al. Treatment outcomes in stage I lung cancer: a comparison of surgery and stereotactic body radiation therapy. J Thorac Oncol 2015; 10: 1776-1784.

41 Chang JY, Senan S, Paul MA, et al. Stereotactic ablative radiotherapy versus lobectomy for operable stage I non-small-cell lung cancer: a pooled analysis of two randomised trials. Lancet Oncol 2015; 16: 630-637.

42 Fernando HC, Timmerman R. American College of Surgeons Oncology Group Z4099/Radiation Therapy Oncology Group 1021: a randomized study of sublobar resection compared with stereotactic body radiotherapy for high-risk stage I non-small cell lung cancer. J Thorac Cardiovasc Surg 2012; 144: S35-S38.

43 Meyers BF, Puri V, Broderick SR, et al. Lobectomy versus stereotactic body radiotherapy for stage I non-small cell lung cancer: post hoc analysis dressed up as level-1 evidence? J Thorac Cardiovasc Surg 2015; 150: 468-471.

44 Cao C, D'Amico T, Demmy T, et al. Surgery versus SABR for resectable non-small-cell lung cancer. Lancet Oncol 2015; 16: e370-e371.

45 Zhang L, Tian J, Wang C. Surgery versus SABR for resectable non-small-cell lung cancer. Lancet Oncol 2015; 16 : e371-e372.

46 Chang JY, Senan S, Smit EF, et al. Surgery versus SABR for resectable non-small-cell lung cancer - Authors' reply. Lancet Oncol 2015; 16: e374-e375.

47 Dearman C, van As N, Crellin A, et al. Surgery versus SABR for resectable non-small-cell lung cancer. Lancet Oncol 2015; 16: e373-e374.

48 Opitz I, Rocco G, Brunelli A, et al. Surgery versus SABR for resectable non-small-cell lung cancer. Lancet Oncol 2015; 16: e372-e373. 

radiotherapy for clinical stage I non-small-cell lung cancer: importance of salvage surgery. J Thorac Oncol 2015; 10: $1616-1624$.

50 Crabtree T, Puri V, Timmerman R, et al. Treatment of stage I lung cancer in high-risk and inoperable patients: comparison of prospective clinical trials using stereotactic body radiotherapy (RTOG 0236), sublobar resection (ACOSOG Z4032), and radiofrequency ablation (ACOSOG Z4033). J Thorac Cardiovasc Surg 2013; 145: 692-699.

51 Safi S, Rauch G, op den Winkel J, et al. Sublobar resection, radiofrequency ablation or radiotherapy in stage I non-small cell lung cancer. Respiration 2015; 89: 550-557.

52 Postoperative radiotherapy in non-small-cell lung cancer: systematic review and meta-analysis of individual patient data from nine randomised controlled trials. PORT Meta-analysis Trialists Group. Lancet 1998; 352: 257-263.

53 Videtic GM, Chang JY, Chetty IJ, et al. ACR appropriateness Criteria early-stage non-small-cell lung cancer Am J Clin Oncol 2014; 37: 201-207.

54 Soldà $\mathrm{F}$, Lodge $\mathrm{M}$, Ashley $\mathrm{S}$, et al. Stereotactic radiotherapy (SABR) for the treatment of primary non-small cell lung cancer; systematic review and comparison with a surgical cohort. Radiother Oncol 2013; 109: 1-7.

55 Fakiris AJ, McGarry RC, Yiannoutsos CT, et al. Stereotactic body radiation therapy for early-stage non-small-cell lung carcinoma: four-year results of a prospective phase II study. Int J Radiat Oncol Biol Phys 2009; 75: 677-682. Cose-response relationship for image-guided stereotactic body radiotherapy of pulmonary tumors: relevance of 4D dose calculation. Int J Radiat Oncol Biol Phys 2009; 74: 47-54. Timmerman R, Paulus R, Galvin J, et al. Stereotactic body radiation therapy for inoperable early stage lung cancer. JAMA 2010; 303: 1070-1076.

58 Timmerman R, McGarry R, Yiannoutsos C, et al. Excessive toxicity when treating central tumors in a phase II study of stereotactic body radiation therapy for medically inoperable early-stage lung cancer. J Clin Oncol 2006; 24: 4833-4839.

59 Olsen JR, Robinson CG, El Naqa I, et al. Dose-response for stereotactic body radiotherapy in early-stage non-small-cell lung cancer. Int J Radiat Oncol Biol Phys 2011; 81: e299-e303.

60 Onishi H, Shirato H, Nagata Y, et al. Hypofractionated stereotactic radiotherapy (HypoFXSRT) for stage I non-small cell lung cancer: updated results of 257 patients in a Japanese multi-institutional study. J Thorac Oncol 2007; 2: 7 Suppl 3, S94-100.

61 Zhang J, Yang F, Li B, et al. Which is the optimal biologically effective dose of stereotactic body radiotherapy for Stage I non-small-cell lung cancer? A meta-analysis. Int J Radiat Oncol Biol Phys 2011; 81: e305-e316.

62 Videtic GM, Hu C, Singh AK, et al. A randomized phase 2 study comparing 2 stereotactic body radiation therapy schedules for medically inoperable patients with stage I peripheral non-small cell lung cancer: NRG Oncology RTOG 0915 (NCCTG N0927). Int J Radiat Oncol Biol Phys 2015; 93: 757-764. Bezjak A, Paulus R, Gaspar LE, et al. Primary study endpoint analysis for NRG Oncology/RTOG 0813 trial of stereotactic body radiation therapy (SBRT) for centrally located NSCLC. Int J Radiat Oncol Biol Phys 2016; 94: 5.

64 Chang JY, Bezjak A, Mornex F, et al. Stereotactic ablative radiotherapy for centrally located early stage non-small-cell lung cancer: what we have learned. I Thorac Oncol 2015; 10: 577-585.

65 Nyman J, Hallqvist A, Lund JA, et al. Stereotactic Precision And Conventional Radiotherapy Evaluation (SPACE) trial. J Thorac Oncol 2015; 10: Sup 2.

Cheung P, Faria S, Ahmed S, et al. Phase II study of accelerated hypofractionated three-dimensional conformal radiotherapy for stage T1-3 N0 M0 non-small cell lung cancer: NCIC CTG BR.25. J Natl Cancer Inst 2014; 106. Bogart JA, Hodgson L, Seagren SL, et al. Phase I study of accelerated conformal radiotherapy for stage non-small-cell lung cancer in patients with pulmonary dysfunction: CALGB 39904. J Clin Oncol 2010; 28: 202-206. Detterbeck FC, Gibson CJ. Turning gray: the natural history of lung cancer over time. J Thorac Oncol 2008; 3: 781-792.

69 Palma D, Visser O, Lagerwaard FJ, et al. Impact of introducing stereotactic lung radiotherapy for elderly patients with stage I non-small-cell lung cancer: a population-based time-trend analysis. J Clin Oncol 2010; 28: 5153-5159.

70 Stanic S, Paulus R, Timmerman RD, et al. No clinically significant changes in pulmonary function following stereotactic body radiation therapy for early- stage peripheral non-small cell lung cancer: an analysis of RTOG 0236. Int J Radiat Oncol Biol Phys 2014; 88: 1092-1099.

71 Takeda A, Kunieda E, Ohashi T, et al. Severe COPD is correlated with mild radiation pneumonitis following stereotactic body radiotherapy. Chest 2012; 141: 858-866.

72 Nagata Y, Hiraoka M, Mizowaki T, et al. Survey of stereotactic body radiation therapy in Japan by the Japan 3-D Conformal External Beam Radiotherapy Group. Int J Radiat Oncol Biol Phys 2009; 75: 343-347.

73 Yamaguchi S, Ohguri T, Ide S, et al. Stereotactic body radiotherapy for lung tumors in patients with subclinical interstitial lung disease: the potential risk of extensive radiation pneumonitis. Lung Cancer 2013; 82: 260-265.

74 Chi A, Liao Z, Nguyen NP, et al. Systemic review of the patterns of failure following stereotactic body radiation therapy in early-stage non-small-cell lung cancer: clinical implications. Radiother Oncol 2010; 94: 1-11.

75 Senthi S, Lagerwaard FJ, Haasbeek CJ, et al. Patterns of disease recurrence after stereotactic ablative radiotherapy for early stage non-small-cell lung cancer: a retrospective analysis. Lancet Oncol 2012; 13: 802-809.

76 Chang JY, Kestin LL, Barriger RB, et al. ACR Appropriateness Criteria(R) nonsurgical treatment for locally advanced non-small-cell lung cancer: good performance status/definitive intent. Oncology (Williston Park) 2014; 28: 706-710 12, 14 passim.

77 Eberhardt WE, De Ruysscher D, Weder W, et al. 2nd ESMO Consensus Conference in Lung Cancer: locally advanced stage III non-small-cell lung cancer. Ann Oncol 2015; 26: 1573-1588.

78 Rodrigues G, Choy H, Bradley J, et al. Definitive radiation therapy in locally advanced non-small cell lung cancer: Executive summary of an American Society for Radiation Oncology (ASTRO) evidence-based clinical practice guideline. Pract Radiat Oncol 2015; 5: 141-148.

79 Rodrigues G, Choy H, Bradley J, et al. Adjuvant radiation therapy in locally advanced non-small cell lung cancer: Executive summary of an American Society for Radiation Oncology (ASTRO) evidence-based clinical practice guideline. Pract Radiat Oncol 2015; 5: 149-155.

80 Aupérin A, Le Pechoux C, Rolland E, et al. Meta-analysis of concomitant versus sequential radiochemotherapy in locally advanced non-small-cell lung cancer. J Clin Oncol 2010; 28: 2181-2190.

81 Mauguen A, Le Péchoux C, Saunders MI, et al. Hyperfractionated or accelerated radiotherapy in lung cancer: an individual patient data meta-analysis. J Clin Oncol 2012; 30: 2788-2797. 
Sampath S, Hall M, Schultheiss TE. Definitive chemotherapy and radiotherapy in patients with stage II non-small cell lung cancer: A population-based outcomes study. Lung Cancer 2015; 90: 61-64.

van Baardwijk A, Wanders S, Boersma L, et al. Mature results of an individualized radiation dose prescription study based on normal tissue constraints in stages I to III non-small-cell lung cancer. J Clin Oncol 2010; 28: $1380-1386$.

Van Schil PE. Salvage surgery after stereotactic radiotherapy: a new challenge for thoracic surgeons. $J$ Thorac Oncol 2010; 5: 1881-1882.

Arriagada R, Bergman B, Dunant A, et al. Cisplatin-based adjuvant chemotherapy in patients with completely resected non-small-cell lung cancer. N Engl J Med 2004; 350: 351-360.

Douillard JY, Rosell R, De Lena M, et al. Adjuvant vinorelbine plus cisplatin versus observation in patients with completely resected stage IB-IIIA non-small-cell lung cancer (Adjuvant Navelbine International Trialist Association (ANITA)): a randomised controlled trial. Lancet Oncol 2006; 7: 719-727.

Scagliotti GV, Fossati R, Torri V, et al. Randomized study of adjuvant chemotherapy for completely resected stage I, II, or IIIA non-small-cell lung cancer. J Natl Cancer Inst 2003; 95: 1453-1461.

Waller D, Peake MD, Stephens RJ, et al. Chemotherapy for patients with non-small cell lung cancer: the surgical setting of the Big Lung Trial. Eur J Cardiothorac Surg 2004; 26: 173-182.

Winton T, Livingston R, Johnson D, et al. Vinorelbine plus cisplatin versus observation in resected non-small-cell lung cancer. N Engl J Med 2005; 352: 2589-2597.

Pignon JP, Tribodet H, Scagliotti GV, et al. Lung adjuvant cisplatin evaluation: a pooled analysis by the LACE Collaborative Group. J Clin Oncol 2008; 26: 3552-3559.

Strauss GM, Herndon JE 2nd, Maddaus MA, et al. Adjuvant paclitaxel plus carboplatin compared with observation in stage IB non-small-cell lung cancer: CALGB 9633 with the Cancer and Leukemia Group B, Radiation Therapy Oncology Group, and North Central Cancer Treatment Group Study Groups. J Clin Oncol 2008; 26: 5043-5051.

Burdett S, Pignon JP, Tierney J, et al. Adjuvant chemotherapy for resected early-stage non-small cell lung cancer. Cochrane Database Syst Rev 2015; CD011430.

Wakelee HA, Dahlberg SE, Keller SM, et al. E1505: Adjuvant chemotherapy+/- bevacizumab for early stage NSCLC: outcomes based on chemotherapy subsets. J Clin Oncol 2016; 34:, abstr. 8507.

Lim E, Harris G, Patel A, et al. Preoperative versus postoperative chemotherapy in patients with resectable non-small cell lung cancer: systematic review and indirect comparison meta-analysis of randomized trials. J Thorac Oncol 2009; 4: 1380-1388.

Felip E, Rosell R, Maestre JA, et al. Preoperative chemotherapy plus surgery versus surgery plus adjuvant chemotherapy versus surgery alone in early-stage non-small-cell lung cancer. J Clin Oncol 2010; 28: 3138-3145.

Scagliotti GV, Pastorino U, Vansteenkiste JF, et al. Randomized phase III study of surgery alone or surgery plus preoperative cisplatin and gemcitabine in stages IB to IIIA non-small-cell lung cancer. J Clin Oncol 2012; 30: 172-178. Alam N, Shepherd FA, Winton T, et al. Compliance with post-operative adjuvant chemotherapy in non-small cell lung cancer. an analysis of National Cancer Institute of Canada and intergroup trial JBR.10 and a review of the literature. Lung Cancer 2005; 47: 385-394.

Booth CM, Shepherd FA, Peng Y, et al. Time to adjuvant chemotherapy and survival in non-small cell lung cancer: a population-based study. Cancer 2013; 119: 1243-1250.

Pepe C, Hasan B, Winton TL, et al. Adjuvant vinorelbine and cisplatin in elderly patients: National Cancer Institute of Canada and Intergroup Study JBR.10. J Clin Oncol 2007; 25: 1553-1561.

Früh M, Rolland E, Pignon JP, et al. Pooled analysis of the effect of age on adjuvant cisplatin-based chemotherapy for completely resected non-small-cell lung cancer. J Clin Oncol 2008; 26: 3573-3581.

Malhotra J, Mhango G, Gomez JE, et al. Adjuvant chemotherapy for elderly patients with stage I non-small-cell lung cancer $\geqslant 4 \mathrm{~cm}$ in size: an SEER-Medicare analysis. Ann Oncol 2015; 26: 768-773.

Arriagada R, Dunant A, Pignon JP, et al. Long-term results of the international adjuvant lung cancer trial evaluating adjuvant Cisplatin-based chemotherapy in resected lung cancer. J Clin Oncol 2010; $28: 35-42$.

Olaussen KA, Dunant A, Fouret P, et al. DNA repair by ERCC1 in non-small-cell lung cancer and cisplatin-based adjuvant chemotherapy. N Engl J Med 2006; 355: 983-991.

Wislez M, Barlesi F, Besse B, et al. Customized adjuvant phase II trial in patients with non-small-cell lung cancer: IFCT-0801 TASTE. J Clin Oncol 2014; 32: 1256-1261.

Huang $\mathrm{H}$, Wang $\mathrm{T}, \mathrm{Hu} \mathrm{B}$, et al. Visceral pleural invasion remains a size-independent prognostic factor in stage I non-small cell lung cancer. Ann Thorac Surg 2015; 99: 1130-1139.

Jiang L, Liang W, Shen J, et al. The impact of visceral pleural invasion in node-negative non-small cell lung cancer: a systematic review and meta-analysis. Chest 2015; 148: 903-911.

Mollberg NM, Bennette C, Howell E, et al. Lymphovascular invasion as a prognostic indicator in stage I non-small cell lung cancer: a systematic review and meta-analysis. Ann Thorac Surg 2014; 97: 965-971.

Kiliçgün A, Turna A, Sayar A, et al. Very important histopathological factors in patients with resected non-small cell lung cancer: necrosis and perineural invasion. Thorac Cardiovasc Surg 2010; 58: 93-97.

Yilmaz A, Duyar SS, Cakir E, et al. Clinical impact of visceral pleural, lymphovascular and perineural invasion in completely resected non-small cell lung cancer. Eur J Cardiothorac Surg 2011; 40: 664-670.

Donnem T, Hald SM, Paulsen EE, et al. Stromal CD8+ T-cell density: a promising supplement to TNM staging in non-small cell lung cancer. Clin Cancer Res 2015; 21: 2635-2643.

Goss GD, O'Callaghan C, Lorimer I, et al. Gefitinib versus placebo in completely resected non-small-cell lung cancer: results of the NCIC CTG BR19 study. J Clin Oncol 2013; 31: 3320-3326.

Kelly K, Altorki NK, Eberhardt WE, et al. Adjuvant erlotinib versus placebo in patients with stage IB-IIIA non-small-cell lung cancer (RADIANT): a randomized, double-blind, phase III trial. J Clin Oncol 2015; 33: 4007-4014. Vansteenkiste J, Zielinski M, Linder A, et al. Adjuvant MAGE-A3 immunotherapy in resected non-small-cell lung cancer: phase II randomized study results. J Clin Oncol 2013; 31: 2396-2403.

Adam V, Wauters I, Vansteenkiste J. Melanoma-associated antigen-A3 vaccination in the treatment of non-small-cell lung cancer. Expert Opin Biol Ther 2014; 14: 365-376.

Groen HJ, van der Heijden E, Klinkenberg TJ, et al. Randomized phase III study of adjuvant hemotherapy with or without low-molecular weight heparin in completely resected non-small cell lung cancer patients: the NVALT-8 study. J Clin Oncol 2016; 34: Suppl, abstr 8506. 